Luziola Spruceana, Papaveraceæ like Hypecoum and Corydalis, and genera like Antirrhinum and Digitalis, on which she has happened to work. She has consulted some old works on the Primulaceæ wrongly interpreted by the previous authors and on the theory of solid carpel and carpel polymorphism, in which no one believes except its author, but makes no mention of some other recent works, especially from the United States. A reference to these would have shown her that evidence for the conservatism of vascular bundles is not so entirely lacking as she believes and that vestigial organs even in the flowers of angiosperms are represented in several instances by their vascular bundles. The Salicaceæ are an example. Fisher ${ }^{3}$ has shown that the simplicity of the flowers of this family is largely due to extreme reduction, and a vestigial vascular supply is present in many instances to organs now greatly reduced or entirely lacking. During the study of the scheme, Chute $^{4}$ has found that sometimes there are abortive ovules without vascular supply, but in other instances an ovular trace is found to a suppressed ovule. Investigating the floral anatomy of the Urticales, Bechtel $^{5}$ finds in several species vascular traces of suppressed perianth leaves, stamens and carpels. In this order the carpel is mostly bicarpellary, but there is a great tendency to the suppression of one carpel. In some instances it almost becomes unicarpellate, but vestigial bundles are always present to show the existence of the second carpel. In some cases the inner whorl of perianth has entirely disappeared, in other instances vestiges of its vascular supply remain. In Stellera (Chamaejasmoe (Thymelaeaceæ), a plant I have studied, the corolla is entirely absent. There is, however, near the base of the flower a much reduced disc-scale. The vascular supply of this clearly indicates it to be a part of much reduced corolla.

All these examples are from the anatomy of the flowers of angiosperms, with which Mrs. Arber deals. As is well known, there are many more instances from other groups of vascular plants.

The position seems to be that it is not always essential for vestigial organs to be represented by their vascular bundles, but in many instances they are, and this seems to have been correctly stated by Bechtel in 1921. "In plant organs suffering reduction, the vascular system either disappears in advance of the organs, or persists as abortive bundles after the organs have disappeared."

Department of Botany,

A. C. Joshr.

Hindu University, Benares. Oet. 1 .

'Arber, A., "Floral Anatomy and its Morphological Interpretation",

New Phyt., 32, 231 ; 1933.
'Bower, F. O., "The Ferns (Filicales)", vol. 1, Cambridge, 1923. "Fisher, M. J." "The Morphology and Anatomy of the Flowers of Salicacex, I and II", Amer. J. Bot., 15, 307, 372; 1928.

Salicacea, , M. M., "The Morphology and Anatomy of the Achene", Amer. J. Bot., 17, $703 ; 1930$.

"Bechtel, A. R., "The Floral Anatomy of the Urticales", Amer. J. Bot., 8, $386 ; 1921$.

Is common with other botanists whose student life began in the nineteenth century, I was brought up to believe that, in the flowering plants, an individual vascular bundle might survive after the complete disappearance of the organ which it supplied in some ancestral stage. In my earlier papers I subscribed to this belief; it is only gradually-and, I may say, with reluctance-that I have come to the conclusion that its foundations are insecure. On reading the work of those who still hold to it, one's first impression may well be that it is supported by ample evidence, but on analysis one finds that this impression is due to the fact that the existence of a lost, ancestral organ is postulated whenever, in the writer's view, it is required.

It is true that, in the paper which Prof. Joshi criticises, I have discussed the question mainly on the basis of my own observations; I have done this deliberately, because there are so many pitfalls in the study of 'vestigial' structures that it is scarcely possible to arrive at a considered opinion about them, except at first hand. All students of floral anatomy are, of course, acqualnted with the memoirs by Prof. A. J. Eames and the long series of papers by research workers at Cornell University who have been inspired by him. In the three papers from this series which Prof. Joshi cites, the idea that certain individual bundles may survive after the total disappearance of the organs which they once supplied-thus offering clues to ancestral structure-is throughout implicit. The writers tend to treat it, not as a hypo. thesis which demands proof, but as a postulate upon which further argument can safely be based. The question, which I have tried to raise, is whether there is sufficient positive evidence to make this assumption valid. Though my own experience has led me to think that there is not, critical study carried over a wider field may show that I am wrong. I hope that Prof. Joshi's letter may lead to a re-examination of the problem by other workers.

$$
\begin{aligned}
& \text { Cambridge. } \\
& \text { Oct. } 26 .
\end{aligned}
$$

Agnes Arber.

\section{A Simple High Resistance}

I was interested to read Prof. Burbidge's account in NATURE for October 28 of a new type of high resistance of simple construction, as a resistance of this type, but of somewhat different design, has been in use in this laboratory for many months as an electrometer leak.

The difficulty in this type of resistance is in the contact between the smoke film and the metal endcaps; the sudden step from the wire-wound end of the rod to the smoke film is liable to give rise to variations in the contact resistance in spite of Prof. Burbidge's treatment of a heavy smoke deposit on the wire winding.

The difficulty has been overcome by silvering the ends of the rod for about $2.5 \mathrm{~cm}$, and copper-plating on the silver. In this way a metal 'thimble' is formed on the end of the rod, with a smooth unbroken surface from the metal on to the glass. Short lengths of sealing-in wire are soldered to the end caps, and the caps and rod covered with a smoke deposit from burning camphor. The resistance is then washed in alcohol, warmed gently to dry it, and enclosed in a glass tube which is evacuated and sealed off.

The resistance in use here is of the order of $10^{10}$ ohms, and for this order of magnitude a glass rod is quite satisfactory. The length of the rod between the end-caps is about $10 \mathrm{~cm}$. and its diameter $5 \mathrm{~mm}$. The coating is firm and uniform.

No originality is claimed for this design of high resistance : a somewhat similar type was described some years ago in an American journal, but $I$ have been unable to trace the paper.

$$
\begin{gathered}
\text { Physics Department, } \\
\text { University College, } \\
\text { Aberystwyth. } \\
\text { Nov. } 8 .
\end{gathered}
$$

